\title{
Abruptio Placentae 116 Cases: Role of PGE1 in Cervical Ripening and Induction of Labor, January 2006-August 2006
}

\author{
Pratibha Devabhaktuni, M. G. S. Nagasree \\ Department of Obstetrics and Gynaecology, Modern Government Maternity Hospital/Osmania Medical College, \\ Hyderabad Telangana, India \\ Email:dpdnk@yahoo.com
}

How to cite this paper: Devabhaktuni, P. and Nagasree, M.G.S. (2018) Abruptio Placentae 116 Cases: Role of PGE1 in Cervical Ripening and Induction of Labor, January 2006-August 2006. Open Journal of Obstetrics and Gynecology, 8, 585-597. https://doi.org/10.4236/ojog.2018.86065

Received: April 16, 2018

Accepted: June 10, 2018

Published: June 13, 2018

Copyright (c) 2018 by authors and Scientific Research Publishing Inc. This work is licensed under the Creative Commons Attribution International License (CC BY 4.0).

http://creativecommons.org/licenses/by/4.0/

\begin{abstract}
OBJECTIVES: In the very high risk obstetric cases of placental abruption, expediting delivery is of utmost urgency, since the complications are related to the abruption delivery interval. Before the introduction of prostaglandins for labor induction, it was a routine practice to do amniotomy and use oxytocin drip to accelerate labor when vaginal delivery was contemplated. We present 116 cases of placental abruption, including the severe cases, managed in the year 2006 during a period of 8 months, at Modern Government Maternity Hospital, which was the biggest maternity hospital in the combined state of Andhra Pradesh, and is the biggest in the state of Telangana, attached to Osmania Medical College. The role of prostaglandin E1 (PGE1), for cervical ripening and labor induction/augmentation has been analyzed in this observational study. A variety of variables including age, parity, gestational age, severity of abruption and maternal and fetal status, associated preeclampsia, Bishop score, availability of blood and blood products, associated complications, all factors influence the management adopted. MATERIAL METHODS: The response to PGE1 induction has been studied in terms of efficacy, the total number of doses of vaginal PGE1 in relation to parity, induction delivery interval, successful vaginal delivery rate, the indications for caesarean delivery, perinatal outcome and complications. A decision was made for either abdominal delivery or vaginal delivery on a case to case basis. A routine amniotomy was performed when the cervical os was open, both for confirmation of diagnosis and to release intra uterine pressure, and also it would help in the acceleration of labor. When the Bishop score was more than six, amniotomy was performed and an oxytocin intravenous drip was started. If the Bishop score was less than six, 25/50 mcg. Misoprostol (PGE1) was placed high in the vagina. OBSERVATIONS: Primies that had abruption were 27/116 $=23.27 \%$ and multies were $89 / 116=76.72 \%$. In our study $68 / 116,(58.62 \%)$ had preec-
\end{abstract}


lamsia. In our series, gestational age at abruption was less than 36 weeks in $89 / 116,(76.72 \%)$ and $>36$ weeks in $27 / 116(23.27 \%)$ at presentation. It is significant to note that $100 / 116$ (86.2\%) were unbooked and $16 / 116(13.79 \%)$ were booked cases at our institute. Vaginal deliveries were $84(74.2 \%)$ and caesarean deliveries were $30(25.8 \%)$ in 116 placental abruptions. There were four maternal deaths $3.4 \%$, two died undelivered. Perinatal mortality in our series was 92/116 (79.3\%). PGE1 induced labours-49: When PGE1 was used for labor induction in 49 women, $40(81.63 \%)$ had vaginal delivery and caesarean delivery was done in $9(18.36 \%)$ cases for non progress of labor. Induction delivery interval was less than 12 hours in 45 (91.83\%), more than 12 hours in 4 (8.1\%). Preterm delivery in PGE1 induced cases was 40/49= $81.63 \%$ versus preterm in 116 cases, $76.72 \%$. This indicates that more numbers of preterm deliveries were allowed vaginal delivery. DISCUSSION: Maternal mortality: Better facilities of transfusion of blood products may have reduced maternal mortality in our series. Government maternity hospital is a public sector tertiary health facility providing free treatment. Early referral would make some difference. Acute defibrination leading to disseminated intravascular cougulation was the cause of three deaths, irreversible haemorrhagic shock in another. CONCLUSION: Induction of labor with PGE1 was useful and effective when cervix was unfavorable and Bishop score was less than six. With PGE1 induction (49) 91.83\% delivered in less than 12 hours. There were no maternal deaths and PPH in 49 women induced with PGE1. Hence PGE1 was safe to use in these emergency high-risk obstetric patients. PGE1 usage to expedite delivery can reduce Caesarean section rate.

\section{Keywords}

Placental Abruption, Antepartum Haemorrhage, PGE1, Misoprostol, Labor Induction

\section{Introduction}

Placental abruption is defined as the premature separation of the implanted placenta, normally located, prior to the delivery of the fetus. The frequency of placental abruption has been reported as $3.75 \%$ and $4.7 \%$ [1] [2]. Earlier, Sarwar et al. [3], reported a prevalence of $4.4 \%$ in their population. Ananth CV et al. [4] hypothesized the criteria that were needed to define placental abruption as "severe" should be clinically meaningful and should include at least one of maternal, disseminated intravascular coagulation (DIC), hypovolemic shock, blood transfusion, hysterectomy, renal failure, or in-hospital death, or fetal, nonreassuring fetal status, intrauterine growth restriction, or fetal death, or neonatal death, preterm delivery, or small for gestational age, complications. The overall prevalence rate of abruption was 9.6 per 1000, of which two-thirds of cases were classified as being severe, 6.5 per 1000 [4]. The prevalence of abruption in European countries is 3 - 6 per 1000 pregnancies, whereas the corresponding data in North America is two-fold higher (7 - 12 per 1000 pregnancies). While the ab- 
ruption rate has plateaued since 2000 in the US, all other European countries show declining rates [5].

Approximately $10 \%$ of all preterm births and up to one third of all perinatal deaths are caused by placental abruption (Ananth et al. 2006, Oyelese and Ananth, 2006) [6] [7]. Among women with placenta previa, the risk of abruption was 3 to 4 fold (Baumann et al. 2000) [8].

The long-term risk of death and morbidity from premature cardiovascular disease are approximately 2 - to 6 -fold higher among women with abruption compared with otherwise normal pregnancies [9]. The risk of premature cardiovascular disease is increased by $70 \%$ in these women (Ray et al. 2005) [10].

Veerbeek H.W. [11] demonstrated a strong association between placental abruption and the presence of cardiovascular disease risk factors after delivery. Cholesterol is an important risk factor for cardiovascular disease, and in women with a history of placental abruption, the cholesterol levels are significantly higher [11]. Biopsy studies obtained in women with placental abruption show a higher prevalence of abnormal spiral artery remodeling, decidual thrombosis, inflammation, and intimal and subintimal thickening (so-called acute atherosis lesions) than that observed in normal pregnancy. Maternal placental syndromes (MPS) that exhibit similar placental bed acute atherosis lesions may serve as markers for subsequent premature cardiovascular disease in that woman [11].

JOGC 2013 [12] has included in the indications for induction of labor as: High Priority: Preeclampsia $\geq 37$ weeks, Significant maternal disease not responding to treatment, Significant but stable antepartum hemorrhage, Chorioamnionitis, Suspected fetal compromise, Term pre-labor rupture of membranes with maternal GBS colonization. Abruptio placenta has also been found to be associated with poor perinatal outcome, including low birth weight, increased incidence of prematurity and still birth.

The risk of severe abruption was substantially higher than mild abruption in relation to chronic hypertension (RR, 1.64 vs. 1.35), mild preeclampsia (RR, 2.06 vs. 1.69), and severe preeclampsia ( $R R, 4.21$ vs. 2.00) [4]. Serious maternal complications occurred in 15.4 per 10,000 for nonabruption and in 33.3 and 141.7 per 10,000 in women for mild and severe abruption. The rate of serious complications for severe abruption remained fairly stable between 2006 and 2010, and increased sharply thereafter [4].

\section{Objectives}

In the very high risk obstetric cases of placental abruption, expediting delivery is of utmost urgency, since the complications are related to the abruption delivery interval. Before the introduction of prostaglandins for labor induction, it was a routine practice to do amniotomy and use oxytocin drip to accelerate labor when vaginal delivery was contemplated. We present 116 cases of placental abruption, including the severe cases, managed in the year 2006 during a period of 8 months at Modern Government maternity hospital, which was the biggest maternity hospital in the combined state of Andhra Pradesh, and is the biggest in 
the state of Telangana, attached to Osmania Medical College. The role of prostaglandin E1 (PGE1), for cervical ripening and labor induction/augmentation has been analyzed in this observational study.

A variety of variables including age, parity, gestational age, severity of abruption and maternal and fetal status, associated preeclampsia, Bishop score, availability of blood and blood products, associated complications, all factors influence the management adopted.

\section{Material Methods}

The response to PGE1 induction has been studied in terms of efficacy, the total number of doses of vaginal PGE1 in relation to parity, induction delivery interval, successful vaginal delivery rate, the indications for caesarean delivery, perinatal outcome and complications. Complete physical and obstetric examination was performed. Fetal heart sounds were confirmed. Blood chemistry and coagulation tests were done. A decision was made for either abdominal delivery or vaginal delivery on a case to case basis. A routine amniotomy was performed when the cervical os was open, both for confirmation of diagnosis and to release intra uterine pressure, and also it would help in the acceleration of labor. When the Bishop score was more than six, amniotomy was performed and an oxytocin intravenous drip was started. If the Bishop score was less than six, 25/50 mcg misoprostol (PGE1) was placed high in the vagina after wetting the tablet but before it becomes powder. The woman is requested to stay in bed for half an hour. When fetus is alive, monitoring of fetal heart was done. Should any deterioration occur in the maternal condition or fetal status or the progress of labour be tardy caesarean delivery was planned.

\section{Observations}

\subsection{Parity}

Primies who had abruption were $27 / 116=23.27 \%$ and multies were $89 / 116=$ $76.72 \%$. In our study 68/116, (58.62\%) had preeclamsia (Table 1 ).

\subsection{Gestational Age at Abruption}

In our series gestational age at abruption was less than 36 weeks in $89 / 116$, (76.72\%) and more than 36 weeks in 27/116 (23.27\%) at presentation. Hence the number of preterm deliveries was $76.72 \%$ (Table 2).

\subsection{Emergency Admissions}

It is significant to note that $100 / 116(86.2 \%)$ were unbooked and $16 / 116$ $(13.79 \%)$ were booked cases at our institute (Table 3).

\subsection{Method of Labor Induction and Augmentation}

When the Bishop score was more than 6 , amniotomy was done and oxytocin infusion was started, in 44 (Table 4). 
Table 1. Number of cases in relation to parity.

\begin{tabular}{ccccc}
\hline Parity & Primies & G 2 & G 3 & G 4 \\
\hline No & 27 & 49 & 23 & 22 \\
$\%$ & 23.27 & 37.93 & 19.82 & 18.92 \\
\hline
\end{tabular}

Note: Primies constituted 23.27\%, Multies: $76.72 \%$.

Table 2. Placental Abruption in relation to gestational age.

\begin{tabular}{ccc}
\hline Gestational age in weeks & No. & $\%$ \\
\hline$<36$ weeks & 89 & 76.72 \\
$>37$ weeks + & 27 & 23.27 \\
\hline
\end{tabular}

Note: Preterm delivery in $76.72 \%$.

Table 3. Emergency admissions.

\begin{tabular}{ccc}
\hline Booked vs. Unbooked & No & $\%$ \\
\hline Booked cases & 16 & 13.79 \\
Unbooked cases & 100 & 86.2
\end{tabular}

Table 4. Method of labor induction and augmentation.

\begin{tabular}{ccc}
\hline Method in vaginal deliveries & No. & $\%$ \\
\hline Bishop score $>$ 6, Amniotomy + Oxytocin & 44 & 37.9 \\
Bishop score $<6$, Amniotomy + PGE1 & 40 & 34.48 \\
Caesarean deliveries & 30 & 25.8
\end{tabular}

Note: Vaginal deliveries were 84 .

When the Bishop score was less than 6, amniotomy was performed and vaginal misoprostol, PGE1 tablet was inserted, 25 or $50 \mathrm{mcg}$ depending on the term of gestation in 49 cases of abruption. Out of 49,40 had vagina delivery and 9 had caesarean delivery due to unsatisfactory progress of labor and other indications.

Vaginal deliveries were 84/116 (74.2\%), 44, (37.9\%) following oxytocin infusion and $40(34.48 \%)$ after misoprostol induction. Caesarean deliveries were 30 (25.8\%) in 116 placental abruptions. Two women died undelivered.

\subsection{Indication for Caesarean Delivery in 30 Cases}

At admission in 21 women a decision was made for abdominal delivery and 9 cases were taken up for C. section due to slow progress of labour following PGE1 induction.

The indications are shown in Table 5.

\subsection{Mode of Delivery and Perinatal Outcome in 116 Cases}

There were 72 cases (62.06\%) with absent fetal heart sounds (IUD) at admission. Stillbirths were 10 . (8.6\%) and neonatal deaths were another 10 (8.6\%). The average birthweight in neonatal deaths was $1.65 \mathrm{Kg}$. Perinatal mortality in our se- 
ries was 92/116 (79.3\%) (Table 6).

\subsection{PGE1 Induced Labors-No. 49. Number of Doses Required for Delivery}

$20 / 49=40.81 \%$ cases delivered with a single dose of $25 \mathrm{mcg}$ of vaginal misoprostol (Table 7).

\subsection{No. of Cases in Relation to Weeks of Gestation}

The gestational age at abruption was 28 weeks in 13 (26.53\%) (Table 8), 28 to 32 wks in $11(22.44 \%), 32$ to 36 in $16(32.65 \%)$ and 37 weeks+ in $9(18.36 \%)$ in 49 PGE1 induced labours.

\subsection{Induction Delivery Interval in 49 Cases}

Induction delivery interval was less than 12 hours in $45 / 49=91.83 \%$ Table 9 .

Table 5. Indication for Caesarean delivery in 30 cases.

\begin{tabular}{cc}
\hline Indication in group A & No. of cases \\
\hline One previous LSCS & 4 \\
Two previous LSCS & 2 \\
Live foetus & 9 \\
Brow presentation & 2 \\
Abruptio + placenta previa & 2 \\
Abruptio + low lying placenta & 2 \\
Group B Failure to progress & 9 \\
\hline
\end{tabular}

Note: Group A: Immediate LSCS N = 21; Group B: Failure to progress with PGE1: 9.

Table 6. Mode of delivery and Perinatal outcome in 116 cases.

\begin{tabular}{cccc}
\hline Perinatal outcome & TOTAL & VD & LSCS \\
\hline IUD at admission & $72(62.06 \%)$ & $63(54 \%)$ & $9(7.75 \%)$ \\
Still births & $10(8.6 \%)$ & $8(6.8 \%)$ & $2(1.7 \%)$ \\
Neonatal deaths & $10(8.6 \%)$ & $6(5.17 \%)$ & $4(3.44 \%)$ \\
Live births & $24(20.68 \%)$ & $11(9.4 \%)$ & $13(11.2 \%)$ \\
\hline
\end{tabular}

Note: Perinatal mortality in our series was $92 / 116$ (79.3\%); the average birthweight in neonatal deaths was $1.65 \mathrm{Kg}$.

Table 7. PGE1 Induced labours, No. 49. Number of doses required for delivery.

\begin{tabular}{cccc}
\hline Dose in mcg & No. doses & No. cases & $\%$ \\
\hline 25 & 1 & 20 & 40.81 \\
25 & $2-5$ & 9 & 18.36 \\
50 & 1 & 11 & 22.44 \\
50 & $2-4$ & 9 & 18.36 \\
\hline
\end{tabular}




\subsection{PGE1 Induction $n=49$, Birth Weight}

Birth weight was less than $1.6 \mathrm{kgs}$ in 27 cases, $55.1 \%$ shown in Table 10.

\subsection{Perinatal Outcome with PGE1 Induction}

Perinatal mortality in PGE1 induced cases was $81.63 \%$. Out of these IUD at admission were $35 / 49=71.42 \%$. Preterm delivery in PGE1 induced cases was 40/49 $=81.63 \%$ versus preterm in 116 cases of abruption, $76.72 \%$ Table 11 .

\subsection{Comparative Studies}

The analyzed data in our study are compared with other Indian as well as international studies [13]-[20]. Year of study, Total number of cases of Abruption, Prevalence, associated preeclampsia/HDP, Preterm deliveries, vaginal deliveries, \% of LSCS,PNMR, MMR, IUD at admission, multies\% Table 12.

Table 8. Labor induction with PGE1 no.49.

\begin{tabular}{ccc}
\hline Weeks of gestation & No. & $\%$ \\
\hline 28 & 13 & 26.53 \\
$28-32$ & 11 & 22.44 \\
$32-36$ & 16 & 32.65 \\
$37+$ & 9 & 18.36 \\
\hline
\end{tabular}

Note: No. of cases in relation to weeks of gestation; Preterm delivery in PGE1 induced cases 40/49= $81.63 \%$; versus preterm in 116 cases $76.72 \%$.

Table 9. Induction delivery interval in 49.

\begin{tabular}{ccc}
\hline Hours & No. & $\%$ \\
\hline Less than 12 hours & 45 & 91.83 \\
More than 12 hours & 4 & 8.1 \\
\hline
\end{tabular}

Table 10. PGE1 Induction $\mathrm{n}=49$, Birth weight.

\begin{tabular}{ccc}
\hline Birth weight in Kgs & No. & $\%$ \\
\hline Less than 1.6 & 27 & 55.1 \\
More than 1.6 & 22 & 44.89
\end{tabular}

Table 11. Perinatal outcome with PGE1 induction.

\begin{tabular}{ccc}
\hline Perinatal outcome & No. of cases & $\%$ \\
\hline IUD at admission & 35 & 71.42 \\
Neonatal deaths & 2 & 4.08 \\
Live births & 9 & 18.36 \\
Stillbirths & 3 & 6.12 \\
\hline
\end{tabular}

${ }^{\star}$ Neonatal deaths 1.2 kgs. In two cases; Perinatal mortality in PGE1 induced cases $81.63 \%$. 
Table 12. Comparative studies: Year of study, Total number of cases of Abruption, Prevalence, associated preeclampsia/HDP, Preterm deliveries, vaginal deliveries, $\%$ of LSCS,PNMR, MMR, IUD at admission, multies\%.

\begin{tabular}{|c|c|c|c|c|c|c|c|c|c|c|c|}
\hline Author & Year & $\begin{array}{c}\text { Total no } \\
\text { prevalence } \\
\%\end{array}$ & Preeclampsia/HDP \% & $\begin{array}{l}\text { Preterm } \\
\%\end{array}$ & $\begin{array}{c}\text { LSCS } \\
\%\end{array}$ & $\begin{array}{l}\text { Vag. } \\
\text { delivery } \\
\%\end{array}$ & $\begin{array}{l}\text { PNMR } \\
\%\end{array}$ & $\begin{array}{c}\text { MMR } \\
\%\end{array}$ & $\begin{array}{c}\text { IUD at } \\
\text { admn. \% }\end{array}$ & $\begin{array}{c}\text { Multies } \\
\%\end{array}$ & $\begin{array}{c}\text { Primies } \\
\%\end{array}$ \\
\hline 1) Downes et al. [13] & $2002-2008$ & $\begin{array}{c}3619 \\
1.6\end{array}$ & $\begin{array}{c}\text { PE \& E-10.9 } \\
\text { Gest. HTN-2.4 } \\
\text { Chronic HTN-3.3 }\end{array}$ & 53.4 & & & & & & 64.3 & \\
\hline $\begin{array}{l}\text { 2) Minna Tikkanen [14] } \\
\text { Finland }\end{array}$ & $1997-2001$ & $\begin{array}{l}198 \\
0.42\end{array}$ & $\begin{array}{c}\text { PE-19-9.6\% } \\
\text { PIH-18-9.1\% } \\
\text { Chronic HTN-9-4.3\% }\end{array}$ & 59 & 91 & & 9.2 & - & & & \\
\hline $\begin{array}{l}\text { 3) Mohd Saeed [15] } \\
\text { Pakistan }\end{array}$ & $2007-2009$ & $\begin{array}{c}100 \\
1.1 \%\end{array}$ & HDP-50 & 36 & 40 & 60 & 50 & 5 & 35 & & \\
\hline 4) Seema Bibi [2] Pakistan & 2006 & $\begin{array}{c}106 \\
4.7 \%\end{array}$ & Gest. HTN-8\% & 54 & 27 & 73 & $25.62 / 1000$ & & $\begin{array}{c}\text { Still births } \\
51 \%\end{array}$ & 92 & \\
\hline $\begin{array}{l}\text { 5) Sarwar I [3] } \\
\text { Pakistan }\end{array}$ & 2003-2004 & $\begin{array}{c}53 \\
4.4 \%\end{array}$ & & & 30.2 & 69.8 & 67.9 & Nil & 58.5 & & \\
\hline $\begin{array}{l}\text { 6) Nazli Hussain [1] } \\
\text { Pakista }\end{array}$ & 2008 & $\begin{array}{c}81 \\
3.75 \%\end{array}$ & 16 & 51 & 45 & 55 & 67 & 2.46 & 65 & & 17 \\
\hline 7 Pitaphrom [16] Thailand & 1995-2004 & $\begin{array}{c}103 \\
0.92 / 1000\end{array}$ & & 56.3 & & & 16.5 & & & & \\
\hline $\begin{array}{l}\text { 8) Sheba Mathavi [17] } \\
\text { IOG, Chennai }\end{array}$ & 2012-2013 & $\begin{array}{l}101 \\
0.76\end{array}$ & HTN-61.3 & & 59 & 41 & 48 & $\begin{array}{c}1.98 \\
2 / 101\end{array}$ & 36.63 & 61.38 & \\
\hline 9) Mrinalini Mitra [18] & 2014-2015 & $\begin{array}{c}58 \\
0.98 \%\end{array}$ & HDP-50 & 48.27 & 65.5 & & 63.79 & Nil & & & \\
\hline 10) Thieba [19] & 2003 & 177 & & & 35.6 & 64.4 & 85.9 & 3.9 & 83.5 & & \\
\hline $\begin{array}{l}\text { 11) Mukherjee S [20] } \\
\text { Mumbai }\end{array}$ & 2007-2009 & $\begin{array}{l}318 \\
4.4\end{array}$ & $\begin{array}{l}\text { HDP-25 (Gest. HTN-15.4, } \\
\text { chronic HTN-1.9 } \\
\text { PE-4.4,E-0.9) }\end{array}$ & & 30 & 70 & 68 & 3.5 & & 81.14 & 18.86 \\
\hline $\begin{array}{l}\text { 12) Pratibha D } \\
\text { Nagasree MGS } \\
\text { Hyderabad }\end{array}$ & 2006 & 116 & 58.62 & 76.72 & 25.86 & 72.41 & 79.31 & 3.4 & 62.06 & 76.72 & 23.28 \\
\hline PGE1 induced & 2006 & $49 / 116$ & & 81.63 & 18.36 & 81.63 & 81.63 & Nil & 71.42 & & \\
\hline
\end{tabular}

\subsection{Complications in Placental Abruption-116 Cases}

Couvelaire uterus was noted in 5 cases, $4.3 \%$, uterus retracted with application of hot mops in addition to medical measures and hysterectomy could be avoided Table 13.

\subsection{Maternal Mortality in Abruptio Placenta}

There were four maternal deaths 3.4\%, two died undelivered. One case was admitted in a state of shock, expired in two hours while resuscitative measures were being instituted. Three women were being treated for disseminated intravascular coagulation, acute defibrination syndrome and coagulation failure. These three women could not be saved. One case with DIC was a case of intrapartum eclampsia, placental abruption was diagnosed after delivery when retroplacental clots were identified Table 14. 
Table 13. Complications in Placental abruption 116 cases.

\begin{tabular}{ccc}
\hline Complication & No. & $\%$ \\
\hline Couvelaire uterus & 5 & 4.3 \\
Hysterectomy & Nil & \\
Eclampsia & 1 & 0.8 \\
Ascites & 2 & 1.72 \\
Maternal mortality & 4 & 3.4 \\
\hline
\end{tabular}

Table 14. Abruptio placenta, 116 Cases maternal mortality.

\begin{tabular}{|c|c|c|c|}
\hline Gravida, gest. age & Condition at admission & Measures taken & Admission death interval \\
\hline 1) G2 P1 L1, 30 weeks & $\begin{array}{l}\text { APH, BP-80 mm Hg. Systolic, } \\
\text { IUD-1.1 Kg }\end{array}$ & $\begin{array}{l}4 \text { units blood transfused. C. Section done. } \\
\text { Relaparotomy, ligation of Tubo ovarian vessels }\end{array}$ & $\begin{array}{l}24 \text { hrs. DIC with intraperitoneal } \\
\text { bleeding }\end{array}$ \\
\hline 2) G4 P3 L3, Term & $\begin{array}{l}\text { APH, BP-120/80 mm Hg.CT-11 } \\
\text { min. Died undelivered }\end{array}$ & 3 units blood, 3 units FFP transfused. ARM done & 8 hrs. DIC \\
\hline $\begin{array}{l}\text { 4) G5 P3 L3 A1, 30-32 } \\
\text { wks. APH in shock }\end{array}$ & $\begin{array}{c}\text { BP not recordable, Shock, Died } \\
\text { undelivered }\end{array}$ & ARM done. 2 units blood transfused & 2 hrs. Hypovolemic shock \\
\hline
\end{tabular}

\section{Discussion}

Parity wise distribution of cases is shown in Table 1 . Primies who had abruption were $27 / 116=23.27 \%$ and multies were $89 / 116=76.72 \%$. In our study $68 / 116$, (58.62\%) had preeclamsia. HDP, preeclampsia and gestational hypertension, were reported in 50\% [8] and $61.2 \%$ [9]. In our series gestational age at abruption was less than 36 weeks in $89 / 116(76.72 \%)$ and $>36$ weeks in $27 / 116$ (23.27\%) at presentation. It is significant to note that $100 / 116(86.2 \%)$ were unbooked and 16/116 (13.79\%) were booked cases. Vaginal deliveries were 84 (74.2\%) and caesarean deliveries were $30(25.8 \%)$ in 116 placental abruptions. There were four maternal deaths $3.4 \%$, two died undelivered. Our caesarean rate is low compared to others.

The maternal mortality $3.4 \%$, C. Section rate $25.8 \%$ compare with the data of another public sector health provider, 3.5\% and 30\% respectively, from Mumbai and Indore [20]. The number of unbooked cases at our institute $86.2 \%$ also is similar to $83.01 \%$ unbooked reported by Mukherjee S. [20].

Preeclampsia and hypertension of $58.62 \%$, preterm deliveries $76.72 \%$, intrauterine foetal death at admission $62.06 \%$, unbooked admissions $86.2 \%$, all these figures indicate that we are dealing with the high risk, very severe forms of AP.

When PGE1 was used for labor induction in 49 women, 40 (81.63\%) had vaginal delivery and caesarean delivery was done in 9 (18.36\%) cases for non progress of labor. Induction delivery interval was less than 12 hours in 45 (91.83\%), more than 12 hours in 4 (8.1\%). Preterm delivery in PGE1 induced cases was $40 / 49=81.63 \%$ versus preterm in 116 cases, $76.72 \%$. This indicates 
that more numbers of preterm deliveries were allowed vaginal delivery. Perinatal mortality in PGE1 induced labors was $81.63 \%$, this is because of preterm delivery in $81.63 \%$ and IUD at admission in $71.42 \%$ and birth weight $<1.6 \mathrm{kgs}$ in $55.1 \%$ in these cases. Opting for vaginal deliveries in cases of intrauterine foetal demise and in cases of abruption at early gestational age could be two reasons for greater perinatal mortality (PNM) in PGE1 induced labors compared to the overall PNMR. In placental abruption induction of labor with misoprostol was reported in $13.04 \%$ from Chennai [17]. Approximately $10 \%$ of women with placenta previa have coexisting abruption (Konje and Taylor, 2001) [21]. We had two cases (1.98\%) of abruption with placenta previa and another two, abruption with low lying placenta (1.98\%). Augmentation of uterine contractions by oxytocin infusion or ripening of cervix by prostaglandins must be done cautiously as the risk of uterine rupture may exist in placental abruption (Konje and Taylor, 2001) [21] associated with low lying placenta.

\subsection{PNMR, the Health of the Neonate and the Surviving Infant}

Placental abruption is associated with an elevated risk of need for neonatal delivery-room resuscitation, NICU admission, and longer NICU length of stay (LOS). Additionally, the finding of elevated risk of both respiratory distress syndrome and apnea among both preterm and term neonates suggests that abruption may be associated with physiologic under development, which has not been previously recognized [12]. Together, the results suggest that neonates in pregnancies complicated by abruption are vulnerable beyond the immediate perinatal time frame [12]. Abruption was also associated with elevated risk of apnea. Of particular note, the estimated risk of all neonatal outcomes remained elevated in the term group and the non-SGA group, which suggests that placental abruption had a direct negative effect on neonatal health [12]. The elevated risk of neonatal apnea may be responsible for the association between abruption and sudden infant death syndrome needs consideration [12].

Intrapartum asphyxia may lead to long term consequences among survivors. Neonates born after placental abruption are more likely to develop cystic periventricular leucomalasia or intraventricular hemorrhage (Spinillo et al. 1993, Gibbs and Weindling, 1994) [22] [23]. The risk increases with prematurity and low birth weight (Spinillo et al. 1993, Gibbs and Weindling, 1994) [22] [23]. Severe abruption increases the risk for cerebral palsy (Spinillo et al. 1993, Thorngren Jerneck and Herbst, 2006) [22] [24]. Placental abruption is also associated with sudden infant death syndrome (Klonoff Cohen et al. 2002, Getahun et al. 2004) [25] [26]. The rate of fetal malformations may be as high as $4.4 \%$ which is two times higher than that in general population. However, even term babies with normal birth weight have a 25 fold higher mortality with abruption (Ananth and Wilcox, 2001) [27]. Kayani [28] reported a study of severe placental abruption complicated by fetal bradycardia, a decision to delivery interval of 20 minutes or less was associated with substantially reduced neonatal morbidity 
and mortality [28]. Changes thought typical of hypoxic-ischaemic insults rarely occur if the duration of profound hypoxia is less than 10 minutes, that has led to the introduction of 'crash' caesarean section and Code green.

All these complications in the neonates leave us in a dilemma, whether to feel happy or worried about the lower PNMR. Increasing caesarean rates to lower PNMR in the very low birth weight group, how justified are these, we need to ponder.

\subsection{Maternal Mortality}

Better facilities of transfusion of blood products may have reduced maternal mortality in our series. Government maternity hospital is a public sector tertiary health facility providing free treatment. Early referral would make some difference. Acute defibrination leading to disseminated intravascular cougulation was the cause of three deaths, irreversible haemorrhagic shock in another.

\section{Conclusion}

Induction of labor with PGE1 was useful and effective when cervix was unfavorable and Bishop score was less than six. With PGE1 induction (49) 91.83\% delivered in less than 12 hours. There were no maternal deaths and PPH in 49 women induced with PGE1. Hence PGE1 was safe to use in these emergency high-risk obstetric patients. PGE1 usage to expedite delivery can reduce Caesarean section rate.

\section{References}

[1] Hossain, N., Khan, N., Sultana, S.S. and Khan, N. (2010) Abruptio Placenta and Adverse Pregnancy Outcome. JPMA, 60, 443-446.

[2] Bibi, S., Ghaffar, S., Pir, M.A. and Yousfani, S. (2009) Risk Factors and Clinical Outcome of Placental Abruption: A Retrospective Analysis. JPMA, 59, 672.

[3] Sarwar, I., Abbasi, A.N. and Islam, A. (2006) Abruptio Placentae and Its Complications at Ayub Teaching Hospital Abbottabad. Journal of Ayub Medical College Abbottabad, 18, 27-31.

[4] Ananth, C.V., Lavery, J.A., Vintzileos, A.M., et al. (2016) Severe Placental Abruption: Clinical Definition and Associations with Maternal Complications. American Journal of Obstetrics \& Gynecology, 214, 272.e1-272.e9.

https://doi.org/10.1016/j.ajog.2015.09.069

[5] Ananth, C.V., Keyes, K.M., Hamilton, A., Gissler, M., Wu, C., Liu, S., Luque-Fernandez, M.A., et al. (2015) An International Contrast of Rates of Placental Abruption: An Age-Period-Cohort Analysis. PLoS ONE, 10, e0125246.

https://doi.org/10.1371/journal.pone.0125246 http://nrs.harvard.edu/urn-3:HUL.InstRepos:17295566

[6] Ananth, C.V., Getahun, D., Peltier, M.R. and Smulian, J.C. (2006) Placental Abruption in Term and Preterm Gestations: Evidence for Heterogeneity in Clinical Pathways. Obstetrics \& Gynecology, 107, 785792. https://doi.org/10.1097/01.AOG.0000207560.41604.19

[7] Oyelese, Y. and Ananth, C.V. (2006) Placental Abruption. Obstetrics \& Gynecology, 
108, 10051016. https://doi.org/10.1097/01.AOG.0000239439.04364.9a

[8] Baumann, P., Blackwell, S.C., Schild, C., Berry, S.M. and Friedrich, H.J. (2000) Mathematic Modeling to Predict Abruptio Placentae. American Journal of Obstetrics \& Gynecology, 183, 815-822. https://doi.org/10.1067/mob.2000.108847

[9] Pariente, G., Shoham-Vardi, I., Kessous, R., Sherf, M. and Sheiner, E (2014) Placental Abruption as a Significant Risk Factor for Long-Term Cardiovascular Mortality in a Follow-Up Period of More than a Decade. Paediatric and Perinatal Epidemiology, 28, 32-38. https://doi.org/10.1111/ppe.12089

[10] Ray, J.G., Vermeulen, M.J., Schull, M.J. and Redelmeier, D.A. (2005) Cardiovascular Health after Maternal Placental Syndromes (CHAMPS): Population-Based Retrospective Cohort Study. Lancet, 366, 1797-1803. https://doi.org/10.1016/S0140-6736(05)67726-4

[11] Rijn, S., Koenen, V. and Franx, A. (2013) Maternal Cardiovascular Risk Profile after Placental Abruption Hypertension.

[12] Induction of Labour. In: Sogc Clinical Practice Guideline, No. 296, September 2013 (Replaces No. 107, August 2001), JOGC SEPTEMBRE 2013.

[13] Downes, K.L., Shenassa, E.D. and Grantz, K.L. (2017) Neonatal Outcomes Associated with Placental Abruption. American Journal of Epidemiology, 186, 1319-1328. https://doi.org/10.1093/aje/kwx202

[14] Tikkanen, M. and Dissrtation (2008) Placental Abruption Studies on Incidence, Risk Factors and Potential Predictive Biomarkers. Helsinki. http://ethesis.helsinki.fi

[15] Saeed, M. and Rana, T. (2011) Fetomaternal Outcome in Pregnancies Complicated with Placental Abruption. Pakistan Journal of Medical and Health Sciences, 5, 140-143.

[16] Pitaphrom, A. and Sukcharoen, N. (2006) Pregnancy Outcomes in Placental Abruption. Journal of the Medical Association of Thailand, 89, 1572-1578.

[17] Sheba Mathavi, S. (2014) A Clinical Study of Incidence, Risk Factors, Maternal and Perinatal Outcome in Pregnancies with Abruptio Placentae. 2012-2014 Dissertation, Institute of Obstetrics and Gynaecology (Madras Medical College) Egmore, Chennai.

[18] Mitra, M. and Rao, B. A One Year Cross Sectional Analysis of Abruptio Placenta in a Tertiary Care Hospital. International Journal of Recent Scientific Research, 7, 8984-8986.

[19] Thieba, B., Lankonade, J., Akotionga, M., Kyelem, C., Ouedraogo, A., Ouerdraogo, C.M., et al. (2003) Abruptio Placentae: Epidemiological, Clinical and Prognostic Aspects with Respect to a 177 Case Series. Gynecologie, Obstetrique \& Fertilite, 31, 429-433. https://doi.org/10.1016/S1297-9589(03)00117-6

[20] Mukherjee, S., Bawa, A.K., Sharma, S., Nandanwar, Y.S. and Gadam, M. (2014) Retrospective Study of Risk Factors and Maternal and Fetal Outcome in Patients with Abruptio Placentae. Journal of Natural Science, Biology and Medicine, 5, 425-428. https://doi.org/10.4103/0976-9668.136217

[21] Konje, J.C. and Taylor, D.J. (2001) Bleeding in Late Pregnancy. In: James, D.K., Steer, P.J., Weiner, C.P. and Gonik, B., Eds., High Risk Pregnancy, 2nd Edition, WB Saunders Co., Edinburgh, 111-128.

[22] Spinillo, A., Fazzi, E., Stronati, M., Ometto, A., Iasci, A. and Guaschino, S. (1993) Severity of Abruptio Placentae and Neurodevelopmental Outcome in Low Birth Weight Infants. Early Human Development, 35, 45-54. https://doi.org/10.1016/0378-3782(93)90138-K 
[23] Gibbs, J.M. and Weindling, A.M. (1994) Neonatal Intracranial Lesions Following Placental Abruption. European Journal of Pediatrics, 153, 195-197. https://doi.org/10.1007/s004310050121

[24] ThorngrenJerneck, K. and Herbst, A. (2006) Perinatal Factors Associated with Cerebral Palsy in Children Born in Sweden. Obstetrics \& Gynecology, 108, 1499-1505.

[25] KlonoffCohen, H.S., Srinivasan, I.P. and Edelstein, S.L. (2002) Prenatal and Intrapartum Events and Sudden Infant Death Syndrome. Paediatric and Perinatal Epidemiology, 16, 82-89.

[26] Getahun, D., Amre, D., Rhoads, G.G. and Demissie, K. (2004) Maternal and Obstetric Risk Factors for Sudden Infant Death Syndrome in the United States. Obstetrics \& Gynecology, 103, 646-652. https://doi.org/10.1097/01.AOG.0000117081.50852.04

[27] Ananth, C.V. and Wilcox, A.J. (2001) Placental Abruption and Perinatal Mortality in the United States. American Journal of Epidemiology, 153, 332-337. https://doi.org/10.1093/aje/153.4.332

[28] Kayani, S.I., Walkinshawa, S.A. and Prestonb, C. (2003) Pregnancy Outcome in Severe Placental Abruption. BJOG: An International Journal of Obstetrics and Gynaecology, 110, 679-683. https://doi.org/10.1046/j.1471-0528.2003.02088.x 